\title{
The Education of One Spouse and the Fatness of the Other Spouse
}

\author{
STANLEY M. GARN, ${ }^{1}$ TIMOTHY V. SULLIVAN, ${ }^{1}$ AND \\ VICTOR M. HAWTHORNE ${ }^{2}$ \\ ${ }^{1}$ Center for Human Growth, University of Michigan Ann Arbor, Michigan \\ 48109-0406, and ${ }^{2}$ Department of Epidemiology, School of Public Health, \\ Ann Arbor, Michigan 48109-0406
}

\begin{abstract}
As shown in 702 wives with 9-12 years of education and 612 husbands similarly educated, the summed skinfolds of one spouse are influenced by the educational level of the other spouse, considerably so for the wives and insignificantly so for the husbands. Women with 9-12 years of education married to men of lower educational attainment are higher in the sum of four skinfolds while women of similar years of schooling married to men of college education and beyond are leaner $(P=0.001)$. Possible explanations for the effect of the education of one spouse on the fatness level of the other spouse include selective mating in the direction set by the husband's socioeconomic milieu and fatness "drift" on the part of the wives, again in the direction of the husband's socioeconomic status (SES). While these findings do not lend themselves to a simple biological explanation, they do reiterate the effects of socioeconomic variables on fatness level within populations and even within families.
\end{abstract}

It is now well known that socioeconomic status (SES) as variously measured relates to the level of fatness in adults of either sex. This is evident in nutrition surveys, both in the United States and abroad, and for Mexicans as well as blacks and whites (Goldblatt et al., 1965; Rimm and Rimm, 1974; Garn and Clark, 1974; Garn et al., 1980; Garn and Ryan, 1981; Garn, 1986; Faranghise et al., 1988; Garn et al., 1988c).

For women in westernized countries the relationship between SES and fatness level is strongly and linearly negative. So, poor and impoverished women tend to be fatter and more often obese (cf. Garn et al., 1988c) while women of high socioeconomic status tend to be leaner (cf. Garn et al., 1984a; Garn, 1986).

For men, in westernized countries, the relationship between education (or income) and fatness level is slightly positive and more often curvilinear, peaking at median income level and for high school graduates. So men of low income or limited education tend to be leaner than their peers, and upper-class males are also leaner than those of middle income or middle class (Garn and Ryan, 1981; Garn, 1986; Garn et al., 1989).
In most of these studies, socioeconomic status (SES) has been that of the family unit and educational level that of the head of the family, so that spousal effects and spousal differences could not be ascertained. Often, this is not a serious limitation, since spouses share the same family income and tend to be of similar educational level. However there are people who "marry down," educationally speaking and those who "marry up." In extreme cases, one spouse may have only grammar school education while the other spouse may have completed college or gone beyond. In such examples of extreme educational diversity and other instances of lesser educational divergence, one wonders how the educational level of one spouse then bears on the fatness level of the other spouse, an intriguing question to human biologists.

In the present study we have given considered attention to just this question, seeking to ascertain how and to what extent the years of schooling of one spouse bears on the fatness level of the other spouse. To do this we have assembled unique samples of

Received May 26, 1988; accepted October 11, 1988. 
men and women of constant educational level and then compared their fatness levels by the educational attainment of their spouses. The results are particularly interesting for education-restricted women who differ markedly in fatness according to their husbands' educational attainment.

\section{MATERIALS AND METHODS}

This study is based upon summed skinfolds and educational data on 612 husbands and 702 wives who participated in the Tecumseh, Michigan Community Health Study at the time of the second "round" of examinations (Napier et al., 1972; Garn et al., 1980, 1988a). All of the participants were of Northwestern European ancestry, married at the time of examination, and derived from a total-population sample with over $90 \%$ initial compliance.

For the purpose of this study, the "husband" sample was restricted to men between 20 and 49 years of age who had attended high school, i.e., with 9-12 years of education. Their mean and median summed skinfold levels were then grouped according to their wives' educational level, as (1) less than high school, (2) high school, and (3) beyond high school. The spouses of these 612 husbands were thus equal in number to the number of husbands, but with a broader educational range.

The sample of "wives" in this study was similarly restricted in the data analysis to 702 women of comparable age who had attended high school (9-12 years of education, and 12 years for the most part). The fatness levels of these women were analyzed according to their husbands' educational level ( $<9$ years, 9-12 years, and $>12$ years). The number of matched husbands necessarily equalled the number of wives of constant (9-12 year) education, but again included a broader educational range, through college and beyond.

The skinfolds totalled four in number (triceps, subscapular, iliac, and abdominal) and the summed skinfold values (Ssf) were calculated without weighting. Since individual skinfolds and the sum of four skinfolds are all highly skewed, with a long tail to the right, both mean and median skinfolds were calculated and included in the tables along with the 3rd moment measure of skewness (Snedecor and Cochran, 1978; Garn et al., 1987). Reliability of individual skinfold measurements exceeded 0.90 for the examination period in questions (Garn et al., 1988a).

With this design it was possible to hold the educational level of 1 spouse constant and then explore the effect of the education of the other spouse. In this way it was also possible to investigate the possible effects of "marrying up" and "marrying down" on the fatness level of husbands and wives, respectively. Since preliminary tests showed that the education-restricted subsamples did not differ in fatness level from the larger sample of husbands and wives (mean normalized $Z$ being 0.003 and 0.001 for the husbands and wives, respectively), no correction for selective loss was found necessary.

Unmarried individuals were of course excluded from the data base and the time of examination was selected to minimize effects of divorce, sickness, death, or moving away from the study area. As a group, the education-restricted wives averaged some 2.2 years younger than the similarly restricted sample of husbands, with mean ages of 33.8 and 31.6 years for these husbands and wives, respectively.

\section{RESULTS}

As shown in Table 1, there is considerable homogamy or assortative mating with respect to educational level in this sample of Tecumseh husbands and wives with 9-12 years of education. Thus, the majority of women with 9-12 years of schooling (73\%) are themselves married to men with comparable educational attainment. Similarly, the majority of men with 9-12 years of formal education are married to women of similar years of schooling (84\%). Overall, spousal correlations for years of education approximate 0.65 for the husbands and the wives, respectively. However, and as shown in the table, women in this sample are equally likely to marry up or marry down, with respect to their husbands' educational attainment. Conversely, the men in this education-restricted sample are signif-

TABLE 1. Educational level of husbands and wives of propositi with 9-12 years of education.

\begin{tabular}{lrrrrr}
\multirow{2}{*}{$\begin{array}{l}\text { Years of } \\
\text { education }\end{array}$} & \multicolumn{2}{c}{ Husbands $^{1}$} & & \multicolumn{2}{c}{ Wives $^{2}$} \\
\cline { 2 - 3 } \cline { 5 - 6 } & \multicolumn{1}{c}{$N$} & & & \multicolumn{1}{c}{$\%$} \\
\hline < years & 86 & 12.3 & 23 & 3.8 \\
9-12 years & 515 & 73.4 & 515 & 84.2 \\
$>12$ years & 101 & 14.4 & 74 & 12.1 \\
\hline
\end{tabular}

${ }^{1}$ Husbands of 702 wives with 9-12 years of education.

Wives of 612 husbands with 9-12 years of education. 
icantly more likely to marry women of higher educational attainment $(12 \%)$ than women of lesser educational level (4\%). This is consistent with the educational distribution in this semiurban, semirural community, with employment opportunities in industry and agriculture for less-educated males.

When we examine the Ssf of educationrestricted women arranged by their husband's educational level, a simple trend emerges (Table 2). Women married to men of lesser educational level ( $<9$ years of schooling) have the highest mean and median summed skinfolds. Women of 9-12 years of education married to men of comparable (9-12 year) educational level are next in order of fatness, both as mean and median skinfold values. Finally, women of 9-12 years education married to men of greater educational attainment are least fat, both by the mean and median values for the sum of four skinfolds. Identical trends can be shown when individual skinfolds are employed (i.e., triceps, subscapular, iliac, or abdominal) or for pairs of skinfolds or triads of skinfolds.

As shown in Table 2, these trends are highly significant $(P=0.001)$ both by $t$ test, comparing mean values, and by Mann-Whitney $U$ test, comparing the median summed skinfold values. Women who "marry down," educationally speaking are far fatter than women (of comparable educational level) who "marry up." Overall, and for mean and median summed skinfolds, women who marry up are $12-28 \%$ leaner than those who marry down, depending upon the statistic employed.

In reporting these differences in measured fatness between women who have married

TABLE 2. Summed skinfolds of propositi by educational level of spouse

\begin{tabular}{|c|c|c|c|c|c|}
\hline \multirow{2}{*}{$\begin{array}{l}\text { Education } \\
\text { of spouse }\end{array}$} & \multicolumn{5}{|c|}{ Summed skinfold thicknesses (mm) } \\
\hline & $N$ & Mean & S.D. & Median & Skewnes \\
\hline \multicolumn{6}{|c|}{ Summed skinfolds of wives } \\
\hline$<9$ years & 86 & 95.8 & 46.5 & 8 & $0.741^{1}$ \\
\hline $9-12$ years & 515 & 90.7 & 44.7 & 79 & $1.025^{1}$ \\
\hline$>12$ years & 101 & $76.4^{2}$ & 34.8 & $74^{3}$ & $0.799^{1}$ \\
\hline \multicolumn{6}{|c|}{ Summed skinfolds of husbands } \\
\hline$<9$ years & 23 & 82.7 & 31.7 & 83 & 0.200 \\
\hline $9-12$ years & 515 & 82. & 36.7 & 80 & $0.424^{1}$ \\
\hline$>12$ years & 74 & 83.9 & 40.3 & 77 & $0.736^{1}$ \\
\hline
\end{tabular}

${ }^{1}$ Significantly skewed by 3rd moment measure (Snedecor and Cochran, 1978, p. 87).

${ }^{2}$ Significantly different from wives of least-educated husbands by $t$ test.

3 Significantly lower than for wives of lesser educated husbands by Mann-Whitney $U$ test (Snedecor and Cochran, 1978, table 10A) up and women (of the same educational level) who have married down, we can exclude age as a relevant factor. The mean ages of the women of 9-12 years of education who married down (33.2), those who married men of equal education (31.2), and those who married up (32.4) are very close, and at most would scarcely account for a 2 $\mathrm{mm}$ difference in the summed skinfolds. (For the women in question, summed skinfolds increase $0.88 \mathrm{~mm}$ per year, between 20 and 49 , in linear fashion.)

When we then explore the summed skinfolds of the men in this series, again educationally restricted to 9-12 years of education, little evidence of a spousal effect appears. Men with high school education married to women with less education ( $<9$ years) are not fatter, at least by the mean summed skinfold values. Similarly, men of 9-12 years of formal education married to women of greater educational attainment (college or beyond) are not leaner. While there is a slight decline in the median summed skinfolds for the men with increasing educational level of their wives, as shown in Table 2 , it is very small (a few millimeters) and not statistically significant by the Mann-Whitney $U$ test. Individual skinfolds of the men are also not significantly different when similarly analyzed with respect to their wives' educational level.

Again, as for the women in the sample, the age factor is not relevant to the fatness of the men. The men who married down, the men who married women of comparable (9-12 years) education and the men who married college-educated women are quite comparable in age at examination (36.2, 33.6 , and 34.8 years, respectively).

Accordingly, the findings in this study are fairly summarized in graphic form, using median summed skinfold values, which are more appropriate given the marked skewness of the skinfold distributions. Figure 1 then reiterates the trends, showing the systematic decrease in fatness for educationrestricted women, according to their husbands' educational level. However, as noted above, there is a similar but not significant trend for the men when grouped by their wives level of education.

\section{DISCUSSION}

As shown in this study, using unique samples of education-restricted men and women, the educational level of the hus- 


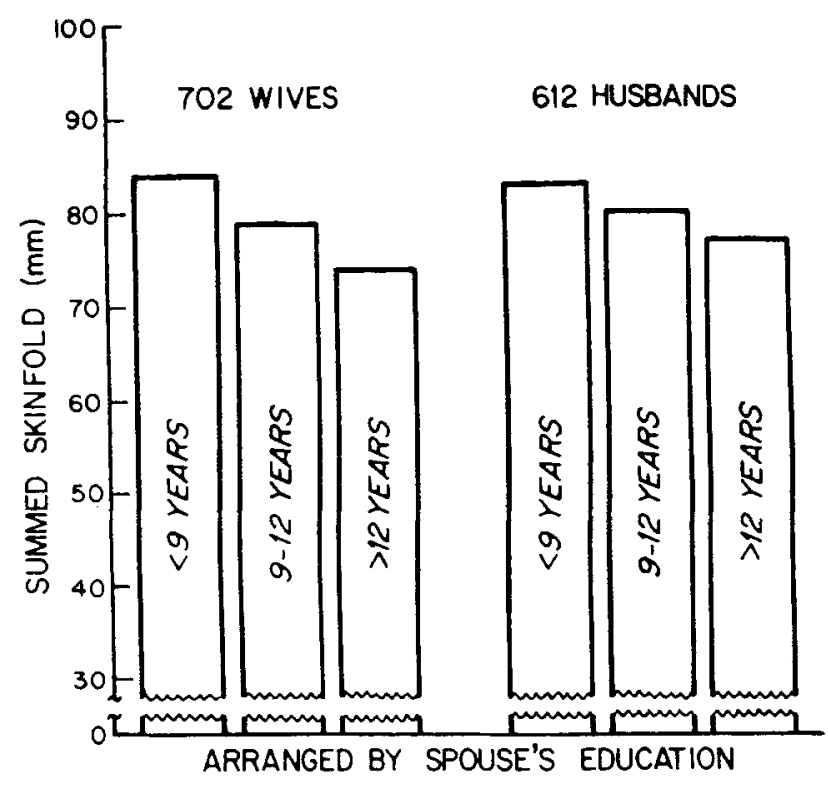

Fig. 1. Relationship between spouses education and medium summed skinfold values of wives (left) and husbands (right). Even with a restricted educational range, the fatness of wives is markedly affected by their husbands' educational attainment whereas the summed skinfolds of husbands are less affected and not significantly so.

bands has a considerable effect on their wives' fatness, even at constant educational level of the latter. In contrast, and using the same investigative design, the wives' educational level has a much smaller and nonsignificant bearing on the summed skinfold values of their husbands.

For women with 9-12 years of education (1-4 years of high school) the act of "marrying down" to a husband with less than 9 years of education is associated with a markedly higher summed skinfold value. Women similarly educated, from the same total population sample but married to husbands with college education or beyond (i.e., "marrying up") are leaner than the average. These differences, which are as much as $28 \%$ when mean skinfold values are used, are not attributable to age effects since the wives are nearly the same age regardless of their husbands' educational lovel.

The men in this study, again drawn from the same total population survey sample, are insignificantly affected by their wives' educational level, when summed skinfolds (or individual skinfolds) are computed. As with the women, there is very little age difference when the men are grouped by their spouses' educational levels so age effects can be discounted.

The systematic effect of the husbands' educational level on the fatness level of their wives, shown in this study, resembles in miniature the inverse relationship between SES and fatness noted in the total sample and among women in other samples previously described. It is difficult to find a biological explanation for this phenomenon, including (among the possibilities) the setpoint explanation, the thermogenesis explanation, the adipocyte-size explanation, and others. Yet among women of constant educational level (9-12 years of education), the educational attainment of the husband bears on the fatness of their wives in systematic fashion.

One possible explanation is selective or assortative mating, such that men select women who resemble those of their own socioeconomic group, even when they marry 
up or marry down, educationally speaking. So men of higher educational level (college or beyond) may select the leaner high school products and men of lower educational level may select the fatter women of 9-12 years of education. Another explanation, which we term "fatness drift," may stem from a tendency for women (once married) to change fatness level in the direction of their husbands' socioeconomic milieu. We have some data, in our fatness-change studies, in support of this latter possibility, since women of low SES do tend to gain more in fatness over the decades than do women of higher family SES (Garn, 1985; Garn et al., 1984b).

Why the fatness of the men (of constant educational level) is so uninfluenced by the educational level of their wives is also problematical, though there are again several possibilities. One possibility is that the women in this population sample did not (or could not) practice deliberate mate selection on the basis of fatness, giving more attention to other criteria. A second possibility is that such selection was limited by the smaller fatness range of their potential husbands, and by the smaller proportion of men (4\%) who married down, with respect to their wives' education.

There are, of course, broader implications here both to morbidity and mortality, since the prevalence of hypertension (both systolic and diastolic) increases markedly with increasing fatness (Garn et al., 1987, 1988b). We might expect the women who married down, and were fatter, to be hypertensive more often than the women who married up, and they are, significantly so. We might also expect the women who married down to have higher lipid levels than those who married up and they do, though the differences in serum cholesterol are not statistically significant. Marrying down or marrying up may therefore bear on such cardiovascular diseases as coronary heart disease (CHD) and stroke, because of differences in fatness rather than self-perceived "stress."

Again, we would like to remind the readers of the complex relationships between SES and fatness level, negatively so in adult women and in curvilinear fashion in adult men. What we have demonstrated here adds to the complexity, in that the fatness of women is further influenced by the educational level of their spouses, even in an educationally restricted group of women drawn from a total population sample. Both the general relationships between the socioeconomic variables and fatness and the special relationships within an education-restricted grouping add to the problem of explaining individual differences in fatness level in simple fashion. We have not dealt with the income variable separately in this study, since husbands and wives share a common family and per capita income or income relative to needs. However, the women who married down did achieve a lower per capita income and the women who married up attained a higher per capita income, so the direction of spousal selection is not independent of family income.

\section{ACKNOWLEDGMENTS}

Funding for this study was provided by a grant from the Weight Watchers Research Foundation. The authors wish to thank Kenneth E. Guire for his help in data management and Audrey Tran for her assistance in manuscript preparation.

\section{LITERATURE CITED}

Faranghise SB, Mueller WH, Hanis CL, Barton SA, and Schull WJ (1988) Socioeconomic status, obesity and non-insulin dependent diabetes in Mexican Americans in Starr County, Texas. Ecol. Food Nutr. 20:163-170.

Garn SM (1985) Continuities and changes in fatness from infancy through adulthood. Curr. Prob. Pediat. 15:1-47.

Garn SM (1986) Family-line and socioeconomic factors in fatness and obesity. Nutr. Rev, 44:381-386.

Garn SM, Bailey SM, and Higgins ITT (1980) Effects of socioeconomic status, family line and living-together on fatness and obesity. In RM Lauer and RB Shekelle (eds.): Childhood Prevention of Atherosclerosis and Hypertension. New York: Raven Press, pp. 187-204.

Garn SM and Clark DC (1974) Economics and fatness. Ecol. Food Nutr. 3:19-20.

Garn SM, Lavelle M, and Pilkington JJ (1984a) Obesity and living together. Marr. Fam. Rev. 7:33-47.

Garn SM, Pilkington JJ, and Lavelle M (1984b) Relationship between initial fatness level and long term fatness change. Ecol. Food Nutr. 14:85-92.

Garn SM and Ryan AS (1981) Replicating the income related reversal of fatness. Eicol. Food Nutr. 10: $237-239$.

Garn SM, Sullivan TV, and Hawthorne VM (1988a) Persistence of relative fatness at different body sites. $H$. Biol. 60:43-45.

Garn SM, Sullivan TV, and Hawthorne VM (1988b) Effect of skinfold levels on lipids and blood pressure in younger and older adults. J. Gerontol. 43:170-174.

Garn SM, Sullivan TV, and Hawthorne VM (1989) Fatness and obesity among the parents of lean probands. Ecol. Food Nutr. (in press).

Garn SM, Sullivan TV, and TenHave T (1987) Which transformation for normalising skinfold and fatness distributions? Lancet $i i: 1326-1327$. 
Garn SM, Sullivan TV, and TenHave T (1988c) Interpreting blood pressure and "modernization" in Brazil. Am. Anthropol. 90:164-165.

Goldblatt PB, Moore ME, and Stunkard AJ (1965) Social factors in obesity. J. Am. Med. Assoc. 192:1039-1044.

Napier JA, Johnson BC, and Epstein FH (1972) The Tecumseh Community Health Study. In II Kessler and
ML Levin (eds.): Case Book of Community Studies. Baltimore: Johns Hopkins Press, pp. 25-46.

Rimm IJ and Rimm AA (1974) Association between socioeconomic status and obesity in 59,556 women. Prev. Med. 3:543-572.

Snedecor GW and Cochran WG (1978) Statistical methods. Ames, Iowa: Iowa State University Press. 